\title{
Positionally cloned asthma susceptibility gene polymorphisms and disease risk in the British 1958 Birth Cohort
}

\author{
J D Blakey, ${ }^{1}$ | Sayers, ${ }^{1}$ S M Ring, ${ }^{2}$ D P Strachan, ${ }^{3}$ I P Hall'
}

\begin{abstract}
- Additional figures are published online only at http:// thorax.bmi.com/content/vol64/ issue 5

${ }^{1}$ Division of Therapeutics and Molecular Medicine, Nottingham Respiratory Biomedical Research Unit, University Hospital Nottingham, Nottingham, UK; ${ }^{2}$ Department of Community Based Medicine, University of Bristol, UK; ${ }^{3}$ Division of Community Health Sciences, St George's Hospital, University of London, UK

Correspondence to: Professor I P Hall, Division of Therapeutics and Molecular Medicine, Nottingham Respiratory Biomedical Research Unit, University Hospital Nottingham, Nottingham NG7 2UH, UK; lan.Hall@nottingham. ac.uk
\end{abstract}

Received 20 May 2008 Accepted 24 January 2009 Published Online First

2 February 2009

\begin{abstract}
Objective: The aim of this study was to estimate the contribution of polymorphisms in the positionally cloned asthma candidate genes ADAM33, PHF11, DPP10, GPRA and PTGDR to the risk of asthma, total and specific immunoglobulin $E$ level, lung function and wheezing in a large, nationally representative, population.

Methods: An association analysis was undertaken using genotype data for tagging and previously associated single nucleotide polymorphisms (SNPS) in regions of these genes and longitudinal phenotype data from singletons of white ethnicity in the British 1958 Birth Cohort DNA archive $(n=7703)$. Population-attributable risk fractions for SNPs showing association were calculated.
\end{abstract}

Results: Polymorphisms producing small but statistically significant increases in asthma risk (OR 1.1 per allele) were identified in DPP10 and ADAM33, with the strongest evidence being for SNPs tagging the DPP10 gene. No individual SNP in any gene under study markedly increased risk for any of the phenotypes in the population studied.

Conclusions: These data suggest that DPP10 and ADAM33 influence asthma risk in the UK population. However, the effects driven by any given locus are small, and genotyping of multiple polymorphisms in many genes will be needed to define a full genetic profile for disease risk.

Over the past 10 years, major efforts have been made using positional cloning approaches to identify genes predicting the risk of developing asthma and related phenotypes. At least 14 genome-wide linkage studies have been undertaken in a range of populations: this has resulted in the identification of a number of potential disease risk genes including ADAM33, PHF11, DPP10 and GPRA $A \cdot{ }^{1-4} \mathrm{~A}$ fifth gene, for the prostanoid $\mathrm{D}$ receptor $(P T G D R)$, was identified using a combination of linkage and candidate gene approaches. ${ }^{5}$ The initial studies on these genes suggested potentially major contributions to disease risk. However, subsequent attempts at replication in small populations have given conflicting results (see Supplementary material). We have therefore utilised the longitudinal phenotypic data from the British 1958 Birth Cohort in order to assess the contribution of these genes to the risk of asthma and related phenotypes in the UK population. We previously used this approach in a similar candidate gene study to investigate the potential role of $A D R B 2$ polymorphism in asthma incidence and prognosis. ${ }^{6}$ The specific aim of this study was to define population-attributable risk for single nucleotide polymorphisms (SNPs) in ADAM33, PHF11, DPP10, GPRA and PTGDR.

\section{METHODS}

\section{Study population and procedures}

The DNA archive established from the British 1958 Birth Cohort (also known as the National Child Development Study) was used. Details of this study population and phenotyping procedures have been reported previously. ${ }^{6-11}$ In brief, 18558 individuals born during 1 week in March 1958 were followed up at ages 7, 11 and 16 years by parental interviews and examinations by school medical officers, and at ages 23,33 and 42 years by means of interviews. The presence of diagnosed asthma or a history of wheezy bronchitis were ascertained by parental interviews in childhood. In adulthood, questionnaires were used to define asthma ever, wheezing ever and wheezing episodes in the previous 12 months. During 2002-2004 all cohort members still in contact with the study team (12 069) and who had not needed a proxy interview were invited to be examined by a trained research nurse at home: 9377 were visited and adequate blood samples for DNA extraction obtained from 8018. Of these, 7703 were singletons of white ethnicity and were included in the present study. The lifetime histories of asthma and wheezing illness for these individuals who were included in the analyses in this study are similar to those who are not included: at age 42 years, the lifetime prevalence of asthma or wheeze in the full cohort was $49.9 \%$ and in the cohort with DNA was $48.8 \%$. Total circulating immunoglobulin E (IgE) and specific IgE to house dust mite, mixed grass pollen and cat fur were measured with a Hytec enzyme immunoassay (Hycor Biomedical, Irvine, CA, USA $\left.{ }^{12}\right)$ at age 45.

Spirometry at age 44-45 years was done in the standing position without nose clips, using a Vitalograph hand-held spirometer as described in full elsewhere. ${ }^{13}$ In the analysis, all readings with a best-test variation $>10 \%$ were excluded. Measures of lung function were adjusted for height and sex, and values with standardised residuals $>3$ SD units were excluded from analyses.

Protocols for the 2002-2004 biomedical examination were approved by the South East MultiCentre Research Ethics Committee. All participants gave informed written consent to participate in genetic association studies and the present study was approved by the oversight committee for the biomedical examination of the British 1958 Birth Cohort. 
Table 1 Risk of self-reported asthma or wheezing illness by age 42 and SNPs in asthma candidate genes

\begin{tabular}{|c|c|c|c|c|c|c|c|c|c|c|}
\hline \multirow[b]{2}{*}{ Gene; SNP } & \multicolumn{2}{|c|}{ Allele } & & \multirow{2}{*}{$\begin{array}{l}\text { Homozygote } \\
\text { allele } 1(\mathrm{n})\end{array}$} & \multirow{2}{*}{$\begin{array}{l}\text { Heterozygote } \\
\text { (n) }\end{array}$} & \multirow{2}{*}{$\begin{array}{l}\text { Homozygote } \\
\text { allele } 2 \text { (n) }\end{array}$} & \multirow[b]{2}{*}{ 2df p Value } & \multirow[b]{2}{*}{ 1df p Value } & \multirow[b]{2}{*}{ OR (per allele) } & \multirow{2}{*}{$\begin{array}{l}95 \% \mathrm{Cl} \text { for } \\
\text { OR }\end{array}$} \\
\hline & 1 & 2 & & & & & & & & \\
\hline Ptgdrs2_441 & G & A & Case & 2017 & 1481 & 242 & 0.400 & 0.201 & 1.05 & 0.98 to 1.13 \\
\hline \multirow[t]{2}{*}{ Ptgdrs3_197 } & A & G & Case & 2873 & 807 & 60 & 0.547 & 0.515 & 0.97 & 0.88 to 1.07 \\
\hline & & & Control & 3012 & 838 & 51 & & & & \\
\hline Ptgdrs rs 17125273 & G & $A$ & Case & 58 & 746 & 2925 & 0.364 & 0.710 & 1.02 & 0.92 to 1.13 \\
\hline & & & Control & 456 & 1770 & 1661 & & & & \\
\hline \multirow[t]{2}{*}{ DPP10 rs13392783 } & \multirow[t]{2}{*}{ G } & \multirow[t]{2}{*}{ A } & Case & 1403 & 1756 & 562 & \multirow[t]{2}{*}{0.024} & \multirow[t]{2}{*}{0.007} & \multirow[t]{2}{*}{1.09} & \multirow[t]{2}{*}{1.03 to 1.17} \\
\hline & & & Control & 1351 & 1880 & 642 & & & & \\
\hline \multirow[t]{2}{*}{ DPP10 rs1430091 } & G & $\mathrm{T}$ & Case & 2213 & 1291 & 200 & 0.388 & 0.171 & 0.95 & 0.88 to 1.02 \\
\hline & & & Control & 2361 & 1298 & 195 & & & & \\
\hline DPP10 rs17048359 & C & $\mathrm{T}$ & Case & 392 & 1615 & 1677 & 0.177 & 0.084 & 0.94 & 0.88 to 1.01 \\
\hline & & & Control & 272 & 1500 & 2086 & & & & \\
\hline PHF11 rs2274282 & G & $\mathrm{T}$ & Case & 2704 & 895 & 75 & 0.539 & 0.503 & 0.97 & 0.88 to 1.06 \\
\hline & & & Control & 2834 & 930 & 65 & & & & \\
\hline PHF11 rs6561533 & G & A & Case & 1162 & 1722 & 717 & 0.702 & 0.95 & 1.01 & 0.95 to 1.08 \\
\hline & & & Control & 1214 & 1767 & 775 & & & & \\
\hline PHF11 rs6561539 & G & C & Case & 89 & 975 & 2660 & 0.677 & 0.387 & 1.04 & 0.95 to 1.14 \\
\hline & & & Control & 89 & 986 & 2811 & & & & \\
\hline GPRA rs323917 & C & G & Case & 3280 & 414 & 12 & 0.233 & 0.216 & 1.09 & 0.95 to 1.24 \\
\hline & & & Control & 3372 & 475 & 9 & & & & \\
\hline GPRA rs323922 & G & C & Case & 560 & 1792 & 1367 & 0.117 & 0.040 & 0.93 & 0.88 to 1.00 \\
\hline & & & Control & 632 & 1904 & 1348 & & & & \\
\hline GPRA rs324377 & C & A & Case & 665 & 1859 & 1198 & 0.218 & 0.084 & 0.95 & 0.89 to 1.01 \\
\hline & & & Control & 2110 & 1538 & 283 & & & & \\
\hline ADAM33 rs574174 & C & $\mathrm{T}$ & Case & 2513 & 1100 & 118 & 0.537 & 0.461 & 1.03 & 0.95 to 1.12 \\
\hline & & & Control & 2571 & 1188 & 118 & & & & \\
\hline ADAM33 rs612709 & G & A & Case & 61 & 860 & 2821 & 0.227 & 0.094 & 0.92 & 0.84 to 1.01 \\
\hline & & & Control & 69 & 957 & 2871 & & & & \\
\hline
\end{tabular}

The $2 \mathrm{df}$ test relates to whether prevalence varies across the three genotypes (without an assumed genetic model). The 1df test assumes a per-allele (additive) model. SNP, single nucleotide polymorphism.

\section{SNP selection}

For each of the genes examined, the SNPs for genotyping were chosen either based on previously published studies identifying putative risk alleles or, where this information was not available in the literature, by choosing tagging SNPs which covered the major haplotype blocks across each gene of interest. A total of four SNPs in $A D A M 33$ (based on our previous meta-analysis, ${ }^{14}$ ), five SNPs in GPRA, six SNPs in DPP10, three SNPs in PHF11 and three SNPs in PTGDR were genotyped (table 1) following SNP selection and quality control in assays using test samples from an in-house DNA archive (see Supplementary information for full details on SNP selection and quality control).

\section{Genotyping}

Genotyping was performed using Taqman technology (Applied Biosystems, Foster City, California, USA) by Geneservice
(Cambridge, UK). Genotyping call rates for each SNP included in this study were $\geqslant 98 \%$. A random selection of 384 -well plates were re-run and concordance on genotype calling was $>99 \%$. We have previously reported high levels of genotyping concordance with a different technology using separately aliquoted DNA from the central archive for rs1042713 and rs1042714 in a subset of 856 individuals. . For one SNP, rs528557, a double heterozygote cluster was seen; these were combined for the present analysis. Only rs6561533 deviated from HardyWeinberg equilibrium (Pearson $\chi^{2} p=0.02$ ), though examination of genotype clustering revealed no apparent problems with allele calling.

\section{Statistical analysis}

Stata version 8.0 was used for cross-tabulations and regression modelling as described in a previous publication. ${ }^{6}$ 
Table 2 Risk of atopy (positive specific immunoglobulin E) at age 45 and SNPs in asthma candidate genes

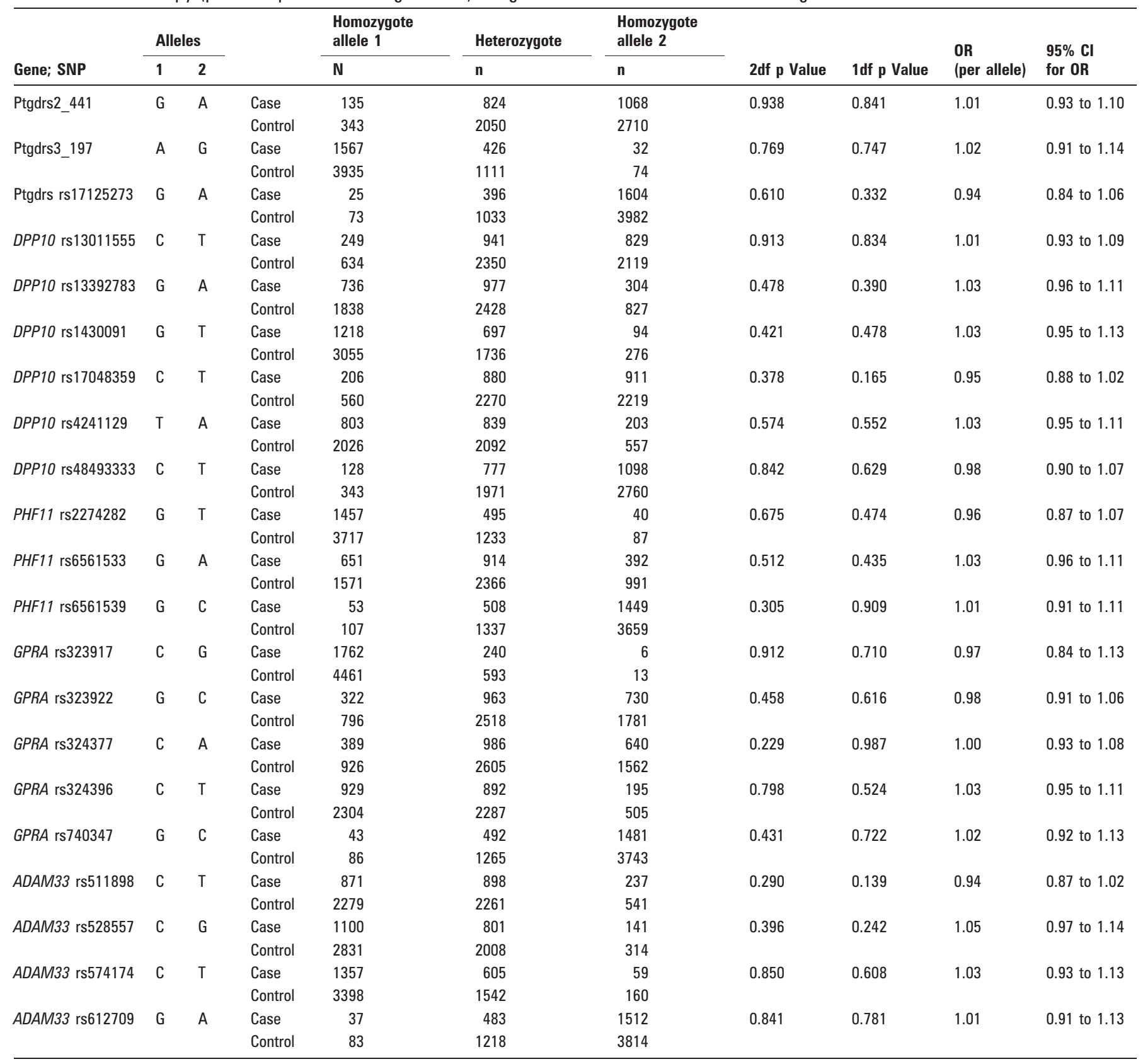

The $2 \mathrm{df}$ test relates to whether incidence varies across the three genotypes (without an assumed genetic model). The 1df test assumes a per-allele (additive) model. SNP, single nucleotide polymorphism.

Asthma prevalence was studied as described previously. ${ }^{6}$ In brief, the major outcomes were: risk of asthma or wheeze by age 42; atopy (defined as the presence of specific IgE to the allergens tested) and total IgE. Secondary analyses were done to study clinical asthma, maturity onset (age $>17$ ) asthma or wheeze, and wheezing in the absence of a diagnosis of asthma.

Haplotype analyses were performed by deriving haplotypes by the EM algorithm implemented in SNPHAP (http://wwwgene.cimr.cam.ac.uk/clayton/software/snphap.txt). For all genes except DPP10, all genotyped SNPs were included and haplotypes with frequency $>10 \%$ used for analyses. For DPP10 there were only two haplotypes with a frequency $>10 \%$; therefore, we derived simpler haplotypes using the loci showing association in the initial SNP analyses. Haplotype analyses were only performed where main effects were seen with at least one SNP in the relevant gene.
The population-attributable risk fraction associated with haplotype variation within each candidate gene was estimated as $(\Sigma \mathrm{f}(\mathrm{R}-1) /(\Sigma \mathrm{f}(\mathrm{R}-1)+1))$, where $\mathrm{f}$ is the frequency of each haplotype and $R$ is the haplotype per copy odds ratio $(O R)$ ).

\section{RESULTS \\ Primary end points}

Tables 1 and 2 show the allelic frequencies of the SNPs studied for the major outcome of this study (asthma/wheeze ever; atopy). Significant associations with asthma or wheeze were seen for rs13011555 and rs13392783 (table 1), in both DPP10 and rs528557 ( $A D A M 33$, also known as S2). A borderline significant association was also seen with rs323922 in GPRA but only under an additive model. However, the highest OR seen for any individual SNP was only 1.1. No significant associations were seen with atopy as measured by specific IgE (table 2). 
Table 3 Risk of developing asthma or wheeze after age 17 years and risk SNPs in DPP10, ADAM33 and GPRA

\begin{tabular}{|c|c|c|c|c|c|c|c|c|c|c|}
\hline Gene; SNP & \multicolumn{2}{|c|}{ Alleles } & $\begin{array}{l}\text { Asthma/wheeze } \\
\text { after age } 17 \text { years }\end{array}$ & $\begin{array}{l}\begin{array}{l}\text { Homozygote } \\
\text { allele } 1\end{array} \\
\mathbf{n}\end{array}$ & $\begin{array}{l}\text { Heterozygote } \\
\mathrm{n}\end{array}$ & $\begin{array}{l}\text { Homozygote } \\
\text { allele } 2\end{array}$ & 2df $p$ Value & 1df $p$ Value & $\begin{array}{l}\text { OR } \\
\text { (per allele) }\end{array}$ & $\begin{array}{l}95 \% \mathrm{Cl} \\
\text { for } \mathrm{OR}\end{array}$ \\
\hline $\begin{array}{l}\text { DPP10 } \\
\text { rs13011555 }\end{array}$ & C & $\mathrm{T}$ & Case & 173 & 611 & 509 & 0.180 & 0.066 & 1.09 & 0.99 to 1.19 \\
\hline \multirow{2}{*}{$\begin{array}{l}\text { DPP10 } \\
\text { rs13392783 }\end{array}$} & G & A & Case & 508 & 608 & 174 & 0.007 & 0.002 & 1.15 & 1.05 to 1.25 \\
\hline & & & Control & 2246 & 3028 & 1030 & & & & \\
\hline GPRA rs323922 & G & C & Case & 198 & 610 & 480 & 0.439 & 0.290 & 0.95 & 0.88 to 1.04 \\
\hline $\begin{array}{l}\text { ADAM33 } \\
\text { rs528557 }\end{array}$ & & & Control & 4370 & 2502 & 425 & & & & \\
\hline
\end{tabular}

The $2 \mathrm{df}$ test relates to whether prevalence varies across the three genotypes (without an assumed genetic model). The $1 \mathrm{df}$ test assumes a per-allele (additive) model. SNP, single nucleotide polymorphism.

None of the SNPs studied showed significant associations with $\log$ total IgE despite the known higher heritability of this trait (data not shown).

\section{Secondary end points}

None of the SNPs studied predicted the incidence of asthma or wheezing from birth to age 16 (data not shown); however, rs13392783 (DPP10) predicted risk of the development of asthma in later life; a weaker association was also seen with this end point for rs574174 (ADAM33 ST+7) (OR 1.09, $\mathrm{p}=0.03)$. rs1430091 in DPP10 predicted risk of clinical asthma (as opposed to wheezing disorders) in the cohort. In contrast, three SNPs in DPP10, rs13011555, rs13392783 and rs17048359, all showed association with lifetime risk of adult wheezing not labelled as asthma. rs13011555 also showed borderline association with lung function, in keeping with the risk allele for lower lung function being the same allele showing association with adult wheezing. Tables 3-6 show data for the main risk SNPs for these secondary end points.

\section{Haplotype analyses}

Given the association seen with the range of SNPs in DPP10, $A D A M 33$ and wheezing/asthma outcomes, we undertook a haplotype-based analysis to identify the major risk haplotype(s) in the Caucasian population. Statistically significant heterogeneity in incidence was evident only for DPP10; this was mainly attributable to variations in adult-onset disease $(p=0.0002)$ and wheezing not labelled as asthma $(p=0.005)$. A simple haplotype analysis using rs13011555 and rs13392783 (see the Methods section for details) showed that the combination T.G had the highest risk for developing phenotypes related to wheezing illness (see table 7): the major risk appears to be for wheezing rather than diagnosed asthma. The proportion of asthma or wheezing illness statistically attributable to common variation in DPP 10 was $7 \%$. Asthma risk was not associated with any haplotype in $A D A M 33$ based upon rs511898, rs528557, rs574174 and rs612709.

In the light of previous published data, we looked specifically at an extended haplotype across GPRA for SNPs rs323917, rs323922, rs324377, rs324396 and rs740347 which had previously been suggested to be associated with asthma risk, C.C.A.C.C, but saw no significant increase in risk of asthma or wheezing phenotypes (OR for asthma/wheeze ever 1.06, 95\% CI 0.95 to 1.19$)$.

\section{DISCUSSION}

Extensive efforts have been invested in attempting to identify genes predicting risk of asthma and related traits using positional cloning approaches. In this study we have assessed the contribution of polymorphisms in the genes identified to date to estimate population-attributable risks. We found evidence supporting a role for DPP1O in the development of wheezing phenotypes, particularly in later life, and also saw weaker associations of SNPs in ADAM33 with progression of wheezing illness. Borderline association with DPP10 and lung function was also seen. Perhaps surprisingly, given the known heritability of the relevant traits, we did not see association of any individual SNP with either atopy or log total IgE, despite reasonable data from linkage studies suggesting a contribution of both DPP10 and PHF11 to these phenotypes. ${ }^{2}{ }^{3}$ The maximum OR seen with risk alleles for wheezing phenotypes was around 1.1. However, as the major allele of these SNPs is often the risk allele for these common complex traits this is perhaps not surprising. Because the major alleles were usually

Table 4 Risk of developing clinical asthma at any age and risk SNPs in DPP10, ADAM33 and GPRA

\begin{tabular}{|c|c|c|c|c|c|c|c|c|c|c|}
\hline Gene; SNP & \multicolumn{2}{|c|}{ Alleles } & $\begin{array}{l}\text { Asthma at } \\
\text { any age }\end{array}$ & $\begin{array}{l}\text { Homozygote } \\
\text { allele } 1\end{array}$ & $\begin{array}{l}\text { Heterozygote } \\
\mathrm{n}\end{array}$ & $\begin{array}{l}\text { Homozygote } \\
\text { allele } 2\end{array}$ & 2df p Value & 1df $p$ Value & $\begin{array}{l}\text { OR } \\
\text { (per allele) }\end{array}$ & $\begin{array}{l}95 \% \mathrm{Cl} \\
\text { for } \mathrm{OR}\end{array}$ \\
\hline DPP10 rs13011555 & C & $\mathrm{T}$ & Case & 103 & 387 & 336 & 0.901 & 0.674 & 1.02 & 0.92 to 1.14 \\
\hline \multirow[t]{2}{*}{ DPP10 rs13392783 } & G & A & Case & 290 & 406 & 124 & 0.598 & 0.942 & 1.00 & 0.90 to 1.11 \\
\hline & & & Control & 2464 & 3230 & 1080 & & & & \\
\hline GPRA rs323922 & G & C & Case & 131 & 392 & 300 & 0.836 & 0.825 & 0.99 & 0.89 to 1.10 \\
\hline \multirow[t]{2}{*}{ ADAM33 rs528557 } & C & G & Case & 472 & 319 & 46 & 0.307 & 0.142 & 0.92 & 0.81 to 1.03 \\
\hline & & & Control & 3726 & 2682 & 458 & & & & \\
\hline
\end{tabular}

The $2 \mathrm{df}$ test relates to whether prevalence varies across the three genotypes (without an assumed genetic model). The 1df test assumes a per-allele (additive) model. SNP, single nucleotide polymorphism. 
Table 5 Risk of developing wheezing illness in the absence of a clinical diagnosis of asthma and risk SNPs in DPP10, ADAM33 and GPRA

\begin{tabular}{|c|c|c|c|c|c|c|c|c|c|c|}
\hline Gene; SNP & \multicolumn{2}{|c|}{ Alleles } & $\begin{array}{l}\text { Wheeze not } \\
\text { asthma any age }\end{array}$ & $\begin{array}{l}\begin{array}{l}\text { Homozygote } \\
\text { allele } 1\end{array} \\
\mathbf{n}\end{array}$ & $\begin{array}{l}\text { Heterozygote } \\
\mathbf{n}\end{array}$ & $\begin{array}{l}\text { Heterozygote } \\
\mathbf{n}\end{array}$ & $\begin{array}{l}\text { 2df } \\
\text { p Value }\end{array}$ & $\begin{array}{l}\text { 1df } \\
\text { p Value }\end{array}$ & $\frac{\mathrm{OR}}{\text { (per allele) }}$ & $\begin{array}{l}95 \% \mathrm{CI} \\
\text { for } \mathrm{OR}\end{array}$ \\
\hline DPP10 rs13011555 & C & $\mathrm{T}$ & Case & 376 & 1373 & 1159 & 0.073 & 0.025 & 1.08 & 1.01 to 1.16 \\
\hline \multirow[t]{2}{*}{ DPP10 rs13392783 } & G & A & Case & 1113 & 1350 & 438 & 0.010 & 0.005 & 1.10 & 1.03 to 1.18 \\
\hline & & & Control & 1641 & 2286 & 766 & & & & \\
\hline GPRA rs323922 & G & C & Case & 429 & 1400 & 1067 & 0.136 & 0.048 & 0.93 & 0.87 to 1.00 \\
\hline \multirow[t]{2}{*}{ ADAM33 rs528557 } & C & G & Case & 1616 & 1144 & 175 & 0.257 & 0.202 & 0.95 & 0.88 to 1.03 \\
\hline & & & Control & 2582 & 1857 & 329 & & & & \\
\hline
\end{tabular}

The $2 \mathrm{df}$ test relates to whether prevalence varies across the three genotypes (without an assumed genetic model). The 1df test assumes a per-allele (additive) model.

SNP, single nucleotide polymorphism.

the risk alleles, calculations of the population-attributable risk suggest that as much as $6-7 \%$ of disease risk in the population is potentially attributable to the SNPs studied in DPP1O and $A D A M 33$. These values are in keeping with estimates derived from a meta-analysis of $A D A M 33^{14}$ and are likely to be typical for risk alleles for asthma. In all we are potentially able to explain a maximum of $<13 \%$ of the total population risk of developing asthma by the polymorphisms studied in DPP1O and $A D A M 33$, implying that other genes must contribute overall to the risk of disease development. These effects were not due to geographical stratification, which for the risk SNPs identified was not statistically significant when analysed by UK regions (data available at www.b58cgene.sgul.ac.uk).

There are several important implications of these findings. First it is clear that studies attempting accurately to define populationattributable risks for specific polymorphisms in risk genes for common polygenic disorders such as asthma are going to require very large study populations. There have been a number of studies in smaller populations, typically of a few hundred individuals, looking at the genes we investigated; most of these studies were thus underpowered to determine risk accurately. During the analysis of this study, the first genome-wide association study in childhood asthma was reported ${ }^{15}$; interestingly, whilst one new region was identified with strong evidence for an asthma-related gene, a number of suggestive regions were identified which would be in keeping with our conclusions at least for this phenotype, suggesting that multiple genes of small effect are involved. It is clear that studies will require many thousands of cases and controls to determine adequately the contribution of specific risk alleles to disease status overall.

Secondly, despite the weak effects of individual SNPs, our data provide support for a role for DPP1O in the development of wheezing disorders, particularly later in life. DPP10 codes for a homologue of dipeptidyl peptidase which cleaves terminal dipeptides from cytokines and chemokines, hence one might think polymorphisms in this gene would be more likely to show association with atopy-related phenotypes. However, in the original study which identified this gene as a potential candidate, two loci were identified: one showing association with IgE levels and one (in a separate LD block) showing association with asthma. ${ }^{2}$ One SNP in each of these regions showed significant association with wheezing phenotypes in this study, but we did not find evidence supporting a contribution of this gene to total IgE. Because of the LD structure of DPP10, the large size of the gene and the lack of knowledge regarding functional polymorphisms, it is conceivable we may have missed an association with atopy by our choice of tagging SNPs. DPP1O was initially identified in families with children with asthma, ${ }^{2}$ and our primary observation of an association with asthma or wheeze by age 42 is consistent with this. It is interesting, therefore, that a secondary analysis suggests that the effect in our study appears to be driven by a relationship with asthma or wheeze of onset after 17 . It is unclear whether the signal for asthma in children in this study is attenuated by noise from factors contributing to non-asthmatic childhood wheezing as we use a composite end point. Additionally, it is uncertain whether the parents in the initial linkage study had a significant degree of asthma of later onset.

The association seen between rs528557 in ADAM33 and wheezing phenotypes is consistent with those previously reported in the literature ${ }^{14^{16-18}}$ in terms of the risk allele. Although a previous meta-analysis ${ }^{14}$ identified this polymorphism as a risk factor for asthma, it is worth emphasising that the total numbers of cases and controls combined in the meta-analysis (2964) is

Table 6 Lung function (FEV 1 in litres) and risk SNPs in DPP10, ADAM33 and GPRA

\begin{tabular}{|c|c|c|c|c|c|c|c|c|c|}
\hline \multirow[b]{2}{*}{ Gene; SNP } & \multicolumn{2}{|c|}{ Alleles } & & \multirow{2}{*}{$\begin{array}{l}\text { Homozygote } \\
\text { allele } 1\end{array}$} & \multirow[b]{2}{*}{ Heterozygote } & \multirow{2}{*}{$\begin{array}{l}\text { Homozygote } \\
\text { allele } 2\end{array}$} & \multirow[b]{2}{*}{ 2df p Value } & \multirow[b]{2}{*}{ Beta per allele } & \multirow[b]{2}{*}{$95 \% \mathrm{Cl}$ for beta } \\
\hline & 1 & 2 & & & & & & & \\
\hline \multirow[t]{2}{*}{ DPP10 rs13011555 } & C & $\mathrm{T}$ & $\mathrm{n}$ & 866 & 3236 & 2868 & 0.047 & 0.03 & 0.00 to 0.03 \\
\hline & & & Mean FEV 1 & $3.27(0.47)$ & $3.31(0.47)$ & $3.31(0.46)$ & & & \\
\hline \multirow[t]{2}{*}{ DPP10 rs13392783 } & G & A & $\mathrm{n}$ & 2515 & 3323 & 1110 & 0.099 & -0.01 & -0.03 to 0.00 \\
\hline & & & Mean $\mathrm{FEV}_{1}$ & $3.3(0.45)$ & $3.30(0.47)$ & $3.33(0.48)$ & & & \\
\hline \multirow[t]{2}{*}{ GPRA rs323922 } & G & C & $\mathrm{n}$ & 1091 & 3369 & 2488 & 0.500 & -0.01 & -0.02 to 0.01 \\
\hline & & & Mean $\mathrm{FEV}_{1}$ & $3.32(0.47)$ & $3.30(0.47)$ & $3.30(0.46)$ & & & \\
\hline \multirow[t]{2}{*}{ ADAM33 rs528557 } & C & G & $\mathrm{n}$ & 3837 & 1820 & 455 & 0.174 & 0.01 & -0.01 to 0.03 \\
\hline & & & Mean $\mathrm{FEV}_{1}$ & $3.30(0.47)$ & $3.30 \pm 0.47$ & $3.34(0.43)$ & & & \\
\hline
\end{tabular}

Regression models adjusted for height, sex, month of year, recent chest infection, and nurse undertaking test (and thus spirometer and area).

$2 \mathrm{df} \mathrm{p}$ Values indicate each genotype at a locus was assigned a separate parameter estimate.

$\mathrm{FEV}_{1}$, forced expiratory volume in $1 \mathrm{~s}$; SNP, single nucleotide polymorphism. 
substantially smaller than the population used for the current study. Furthermore, this polymorphism has also been associated with decline in lung function ${ }^{16}$ which may explain its association with wheezing but not a diagnosis of asthma. However, the size of effect we report is smaller than that previously seen, and no significant effect was seen on lung function.

In contrast to $A D A M 33$ and $D P P 10$, we were unable to identify robust associations between any relevant end point and the SNPs chosen in PHF11, PGDR or GPRA. We extended our analysis of GPRA to look at the possible association between the major risk haplotype previously identified in the PARSIFAL population at this locus but did not identify a significant association. This suggests that previously defined risk alleles/haplotypes within these three genes do not appear to predict risk of asthma or allergic disease in the UK population. These data contrast with a recent study where association was seen with SNPs upstream of GPRA.${ }^{19}$ That study differs from the data presented here in several key aspects: it included data from both American non-Hispanic white and Costa Rican populations, all cases were children, measurements were taken at a single time point and family-based analysis techniques were used. The study also genotyped approximately four times as many SNPs but each population was $<500$ individuals, raising the possibility of false-positive association explaining the findings.

The data we present have not been corrected for multiple testing. It is difficult to know the best way to do this, given that there were a priori reasons for suspecting the genes studied would be linked to asthma risk, and that effects would probably be additive between different genes. The SNPs and phenotypes are not truly independent variables, and hence comprehensive correction for multiple testing would be overly conservative. Hence we have chosen to present the data uncorrected. If one were to apply a Bonferroni correction in order to control the family-wise error rate at the level of the number of genes examined, then the associations with DPP10 would remain significant. Had the extremely conservative approach of correcting at the level of the effective number of independent SNPs (following the method of Nyholt ${ }^{20}$ ) been used, rs13392783 would still have shown significant association with adult-onset asthma or wheeze.

In conclusion, this study suggests that a genetic risk profile for the development of asthma and/or allergic disease in general is likely to require information on multiple SNPs in a large number of genes, and raises the question of how, even if such a profile could be derived, it would be feasible to evaluate prospectively the predictive value of a complex profile without access to extremely large populations probably involving tens of thousands of cases and controls.

Acknowledgements: This study was funded in part by Asthma UK grant no: $05 / 55$. The 2002-4 biomedical survey and DNA collection were funded by Medical Research Council grant no, G0000934. We are especially grateful to all members of the British 1958 Birth Cohort who participated in the field studies and who gave consent for the use of their DNA for genetic epidemiological analyses, and to the research nurses who contributed to the completion of field studies. We are additionally grateful for helpful discussions with WOCM Cookson on study design.

Competing interests: None.

Ethics approval: Protocols for the 2002-2004 biomedical examination were approved by the South East MultiCentre Research Ethics Committee. The present study was approved by the oversight committee for the biomedical examination of the British 1958 Birth Cohort.

Patient consent: All participants gave informed written consent to participate in genetic association studies.

Contributors: JB, IPH and DPS designed this study. DPS and SMR were responsible for the management of the 1958 birth cohort genetic resource. SNP selection was performed by JB and IS. JB was responsible for genetic data handling. Statistical 
analysis was performed by DPS with input from IPH. The manuscript was drafted by IPH and JB: all authors reviewed and revised the manuscript and approved the final version.

\section{REFERENCES}

1. Van Eerdewegh $\mathbf{P}$, Little RD, Dupuis J, et al. Association of the ADAM33 gene with asthma and bronchial hyperresponsiveness. Nature 2002;418:426-30.

2. Allen M, Heinzmann $A$, Noguchi $E$, et al. Positional cloning of a novel gene influencing asthma from chromosome 2q14. Nat Genet 2003;35:258-63.

3. Laitinen T, Polvi A, Rydman P, et al. Characterization of a common susceptibility locus for asthma-related traits. Science 2004;304:300-4.

4. Zhang Y, Leaves NI, Anderson GG, et al. Positional cloning of a quantitative trait locus on chromosome $13 q 14$ that influences immunoglobulin $E$ levels and asthma. Nat Genet 2003;34:181-6.

5. Oguma T, Palmer LJ, Birben E, et al. Role of prostanoid DP receptor variants in susceptibility to asthma. N Engl J Med 2004;351:1752-63.

6. Hall IP, Blakey JD, Al Balushi KA, et al. Beta2-adrenoceptor polymorphisms and asthma from childhood to middle age in the British 1958 birth cohort: a genetic association study. Lancet 2006;368:771-9.

7. Strachan DP, Butland BK, Anderson HR. The incidence and prognosis of asthma and wheezing illness from early childhood to age 33 in a national British cohort. BMJ 1996;312:1195-9.

8. Strachan DP, Griffiths JM, Anderson HR, et al. Ventilatory function in British adults after asthma and wheezing illness at ages 0-35. Am J Respir Crit Care Med 1996;154:1629-35.

9. Power C, Elliott J. Cohort profile: 1958 British birth cohort (National Child Development Study). Int J Epidemiol 2006;35:34-41.

10. Anderson HR, Pottier AC, Strachan DP. Asthma from birth to age 23: incidence and relationship to prior and concurrent atopic disease. Thorax 1992;47:537-42.
11. Johnston IDA, Strachan DP, Anderson HR. Longitudinal study of the effect of pneumonia and whooping cough in childhood on adult lung function. $N$ Eng/ J Med 1998;338:581-7.

12. Nolte H, DuBuske LM. Performance characteristics of a new automated enzyme immunoassay for the measurement of allergen-specific IgE. Summary of the probability outcomes comparing results of allergen skin testing to results obtained with the HYTEC system and CAP system. Ann Allergy Asthma Immunol 1997;79:2734.

13. Fuller E, Power C, Shepherd P, et al. Technical Report on the National Child Development Study Biomedical Survey 2002-2004. www.cls.ioe.ac.uk (accessed March 2009).

14. Blakey J, Halapi E, Bjornsdottir US, et al. Contribution of ADAM33 polymorphisms to the population risk of asthma. Thorax 2005:60:274-6.

15. Moffatt MF, Kabesch M, Liang L, et al. Genetic variants regulating ORMDL3 expression contribute to the risk of childhood asthma. Nature 2007:448:470-3.

16. van Diemen CC, Postma DS, Vonk JM, et al. A disintegrin and metalloprotease 33 polymorphisms and lung function decline in the general population. Am J Respir Crit Care Med 2005:172:329-33.

17. Howard TD, Postma D, Jongepier $\mathrm{H}$, et al. Association of a disintegrin and metalloprotease 33 (ADAM33) gene with asthma in ethnically diverse populations. J Allergy Clin Immunol 2003;112:717-22.

18. Werner M, Herbon N, Gohlke $\mathrm{H}$, et al. Asthma is associated with single-nucleotide polymorphisms in ADAM33. Clin Exp Allergy 2004;34:26-31.

19. Hersh CP, Raby BA, Soto-Quirós ME, et al. Comprehensive testing of positionally cloned asthma genes in two populations. Am J Respir Crit Care Med 2007;176:84957.

20. Nyholt DR. A simple correction for multiple testing for single-nucleotide polymorphisms in linkage disequilibrium with each other. Am J Hum Genet 2004;74:765-9.

\section{Drug and Therapeutics Bulletin (DTB)}

\section{Your key source of unbiased, independent advice}

For over 45 years DTB has been an independent, indispensable part of evidence-based clinical practice. DTB offers healthcare professionals detailed assessment of, and practical advice on, individual medicines and other treatments, groups of treatment and the overall management of disease.

DTB is now also available online at http://dtb.bmj.com:

- browse or search all DTB content from the latest issue back to 1994

- email alerting, sophisticated searching, RSS feeds and full text links from cited references

- interactive services such as My Folders for quick access to articles that you have viewed previously and My Searches to save and re-use useful searches

- comment online on any DTB article

To subscribe, or for further information, please visit http://dtb.bmj.com 